\title{
Diamond, Diamond-Like Carbon (DLC) and Diamond-Like Nanocomposite (DLN) Thin Films for MEMS Applications
}

\author{
T. S. Santra ${ }^{1}$, T. K. Bhattacharyya ${ }^{2}$, P. Patel ${ }^{3}$, F. G. Tseng ${ }^{1}$ and T. K. Barik ${ }^{4}$ \\ 1 Institute of Nanoengineering and Microsystems (NEMS), \\ National Tsing Hua University, Hsinchu, Taiwan \\ ${ }^{2}$ Department of Electronics and Electrical Communication Engineering, \\ Indian Institute of Technology, Kharagpur, West Bengal, \\ ${ }^{3}$ Department of Electrical and Computer Engineering, \\ University of Illinois at Urbana Champaign, \\ ${ }^{4}$ School of Applied Sciences and Humanities, Haldia Institute of Technology, Haldia, \\ Purba Medinipur, West Bengal, \\ ${ }^{1}$ Republic of China \\ ${ }^{2,4}$ India \\ ${ }^{3} U S A$
}

\section{Introduction}

Amorphous carbon films have been utilized in many types of engineering systems and adapted to fulfill a wide variety of applications. The uses of surface coatings are mainly to protect structural materials from high temperature environments or to confine the electric charge largely on interfaces between materials with differing electronic properties mainly for enormous commercial significance. Diamond, Diamond-like Carbon (DLC) and Diamond-like Nanocomposite (DLN) thin films are based on amorphous carbon films. Diamond, DLC and DLN thin films has generated a great interest in the academia due to its fundamental and technological importance. Presently, researchers have given much attention to fabricate the Micro- or Nano- electromechanical systems (MEMS/NEMS) with different types of materials. The characteristics lengths of these technologies are micrometer to nanometer range. MEMS are defined as miniature devices which combining with mechanical, electrical, optical, and biological fields to fabricate integrated circuits (IC) or other similar manufacturing devises. The applications of these MEMS technologies are in different vast areas, like biomedical, environmental, transportation, manufacturing, robotics, space sciences, computing systems etc [1-5]. Researchers have much expectation of these new frontier technologies after silicon-based microelectronic technologies. For excellent MEMS devices, the coating materials should have the properties like high hardness, high modulus of elasticity, high thermal conductivity and tensile strength, high fracture toughness, low surface roughness, very low coefficient of friction, low thermal expansion, high band gap energy, high transmission capability etc. All of these unique and attractive 
properties present in Diamond, Diamond-like Carbon (DLC) and Diamond-like Nanocimposite (DLN) based thin films [6-14]. The amorphous carbon films based MEMS are fully dominated the silicon-based MEMS technologies. The silicon-based MEMS with mechanical loading have lack of high fracture toughness facing with high reliability. Under some extreme conditions like very high temperature or very high particle radiation, silicon may fail to sustain these properties. However, silicon have very large coefficient of friction, high surface energy, high wear rate and small band gap energy, which cannot fulfill the all material properties of MEMS [15-18]. To overcome these drawbacks of silicon materials, researchers are continuously trying to look for new materials for MEMS applications. Ceramics (wide band gap), semiconductors (such as SiC), Polymers (PDMS, PMMA), can play important role for MEMS fabrications. Except these materials, diamond, diamond-like carbon (DLC) and diamond-like nanocomposite (DLN) etc are promising materials for MEMS applications. High elasticity and tensile strength of DLC and DLN films can suitable for high frequency MEMS devices. The temperature withstanding capability of both DLC and DLN films is up to $600{ }^{\circ} \mathrm{C}$ or slightly more. The biocompatibility of DLC and DLN films is strongly effective for biosensors in diagnostics and therapies, surface coatings for surgical instruments, prosthetic replacements etc. Chemically modified DLC and DLN surfaces can act as sensing trace of gases to detect biomolecules in biological research. We have presented a brief review about the latest properties of different amorphous carbon based diamond, Diamond-like Carbon (DLC) and Diamond-like Nanocomposite (DLN) thin films and their application in MEMS/NEMS devices.

\section{Preperation of diamond films}

Diamond, Diamond-like carbon (DLC) and Diamond-like Nanocomposite (DLN) exist in different form of amorphous carbon based thin films have generated a great interest in the academia due to its fundamental and technological importance. The carbon materials which arises from the strong dependence of their physical properties of the ratio of

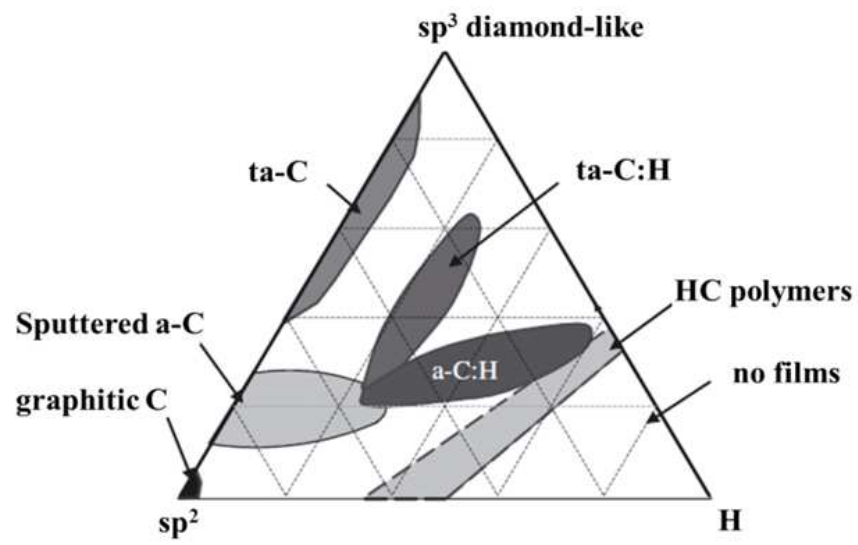

Fig. 1. Ternary phase diagram of amorphous carbons. The three corners correspond to diamond, graphite and hydrocarbons respectively, ([21], permission to reprint obtained from Royal Society London). 
$\mathrm{sp}^{2}$ (graphite-like) to $\mathrm{sp}^{3}$ (diamond-like) bonds. The amorphous carbon is a mixture of $\mathrm{sp}^{2}$, $\mathrm{sp}^{3}$ and $\mathrm{sp}^{1}$ sites with the presence of nitrogen and hydrogen. The nitrogen free carbon films are shown in Fig. 1 on ternary phase diagram. In this figure, the phase diagram defines the regions of pure carbon (designated a-C), tetrahedral amorphous carbon (ta-C), and hydrogenerated amorphous carbon $(\mathrm{a}-\mathrm{C}: \mathrm{H})$ with the corresponding extent of hydrogenation [19-21]. To increase the degree of $\mathrm{sp}^{3}$ carbon bonding, better amorphous carbon (a-C) films can be produced by any kind of deposition systems. If $\mathrm{sp}^{3}$ carbon bonding is very high, then this a-C can be denoted as a tetrahedral amorphous carbon (ta-C) [22]. Fig. 1 shows amorphous hydrocarbon $(\mathrm{a}-\mathrm{C}: \mathrm{H})$ or diamond like films, but it is not higher order due to large hydrogen content. To achieve less hydrogen content with much more $\mathrm{sp}^{3}$ bond, plasma enhanced chemical vapour deposition (PECVD) technique is ideal to generate tetrahedral amorphous carbon films [20]. The $\mathrm{sp}^{3}$ content influence the mechanical properties of the films. The mechanical and wear resistance properties are more prominent with increase of hydrogen content into the films. On the other hand, surface energy and coefficient of friction decreases with greater hydrogen passivation into the films. Again, the $\mathrm{sp}^{2}$ content influences the electronic properties of the films.

Diamond, Diamond-Like Carbon (DLC) and Diamond-Like Nanocomposite (DLN) thin films can be deposited by different chemical vapor deposition technique like plasma enhanced CVD, plasma assisted CVD, microwave plasma CVD or a hot filament [23-27], ion beam deposition, pulsed laser ablations, filtered cathodic arc deposition, magnetron sputtering etc. The DC plasma jet chemical vapor deposition can be used for Diamond like carbon films deposition also [28]. Table 1 shows the different properties of diamond films [29-31, 6].

\begin{tabular}{lccccc}
\hline & a-C:H (DLC) & ta-C (DLC) & UNCD & Diamond & DLN \\
\hline H $($ atomic $\%)$ & 30 & 0 & 0 & $<0.1$ & --- \\
$\mathrm{Sp}^{3}$ fraction & $<0.5$ & $>0.8$ & $>0.9$ & $\sim 1.0$ & $0.5-0.8$ \\
Density $\left(\mathrm{Kg} / \mathrm{m}^{-3}\right)$ & 2350 & 3260 & 3500 & 3515 & --- \\
$\mathrm{E}(\mathrm{GPa})$ & 300 & 757 & 300 & 1050 & $90-160$ \\
Hardness $(\mathrm{GPa})$ & $<15$ & $>20$ & $>45$ & 45 & $9-17$ \\
Residual stress $(\mathrm{GPa})$ & $1-2$ & $8-10$ & 0 & 0 & -- \\
\hline
\end{tabular}

Table 1. Different parameters of Diamond, Diamond-Like Carbon (DLC) and Diamond-Like Nanocomposite (DLN) thin films.

In this section, we describe diamond-like carbon deposition by plasma which consists of argon (99.998\%), hydrogen (99.9\%) and $\mathrm{CH}_{4}(99.5 \%)$ is used as a carbon source and is mixed into the plasma jet. The plasma jet is sprayed onto a substrate fixed on a water-cooled substrate holder. The hydrocarbon species in the gas phase for the $\mathrm{CH}_{4}-\mathrm{Ar}-\mathrm{H}_{2}$ gas system, temperatures $\left(500{ }^{\circ} \mathrm{C}\right.$ to $\left.6000{ }^{\circ} \mathrm{C}\right)$ and a total pressure of $0.25 \mathrm{~atm}(25 \mathrm{KPa})$ has been computed using the thermodynamic computer program. The deposition was performed on $\mathrm{Si}(111)$ surface with the growth rate $80 \mu \mathrm{m} / \mathrm{hr}$ The $\mathrm{CH}_{4} / \mathrm{H}_{2}$ gas ratio and substrate temperature influence the properties of diamond. Fig. 2 shows the Scanning Electron Microscopy (SEM) morphology of DLC thin films [28]. Diamond-like Carbon (DLC) and Diamond-like Nanocomposite (DLN) are is basically amorphous carbon based films. In amorphous carbon structure, there is a possibility to form both threefold coordinate $\left(\mathrm{sp}^{2}\right.$ site) as in graphite and fourfold coordinate ( $\mathrm{sp}^{3}$-site) as in diamond [32]. Each of the four valance electron lies in the $\mathrm{sp}^{3}$-site forms $\sigma$-bonds with neighbors [33]. In $\mathrm{sp}^{2}$-site, only 
three electrons are used in $\sigma$-bonds and the forth electron forms a $\Pi$-bond, which lies normal to the $\sigma$-bonding plane. In $\mathrm{sp}^{2}$-site, only the $\Pi$-bond is weakly bonded, and hence, it usually lies closest to the Fermi level and controls the electronic properties of the films. On the other hand, in $\mathrm{sp}^{3}$-site, the $\sigma$-bond controls the mechanical properties of the films [34]. These electrical and mechanical properties are very important parameters for every DLC and DLN based materials.
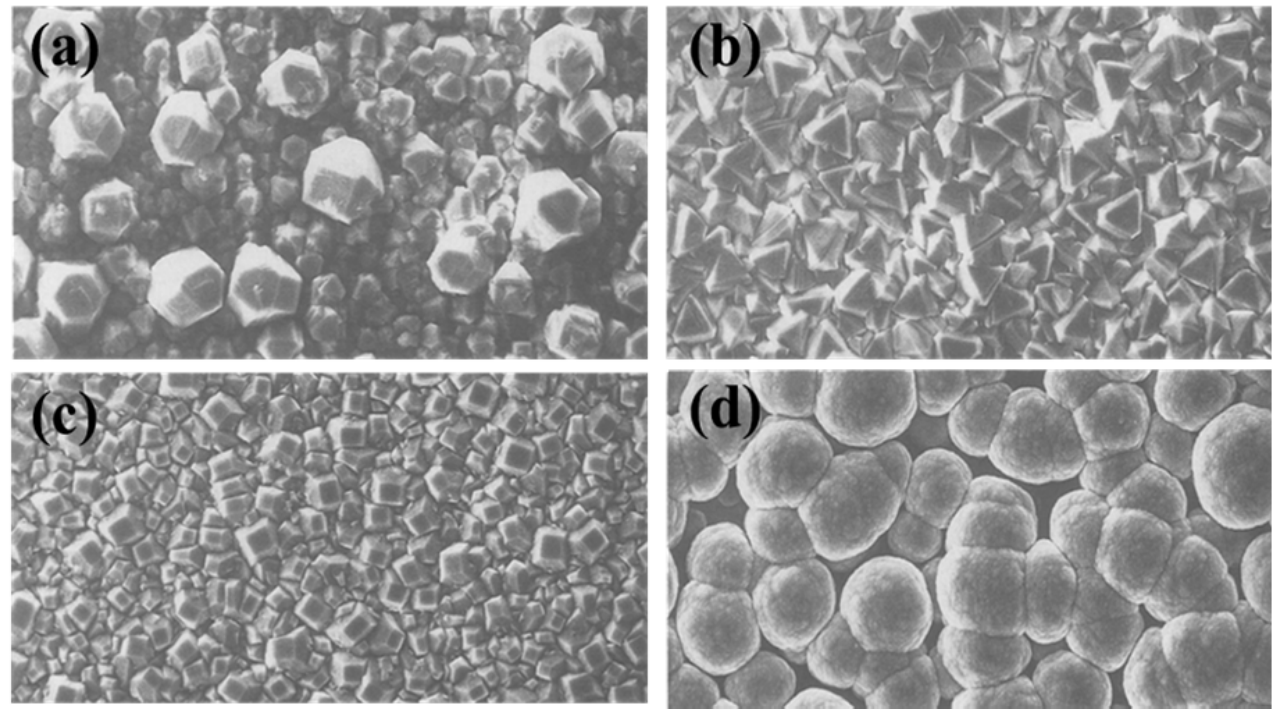

Fig. 2. SEM micrographs of diamond film surfaces deposited at different $\mathrm{CH}_{4} / \mathrm{H}_{2}$ ratios. (a) $1 \%$ (b) $2 \%$, (c) $5 \%$ and (d) $8 \%$. ( - Scale bar $20 \mu \mathrm{m}$ for all figures), ([28], permission to reprint obtained from Elsevier).

\section{Properties of diamond films}

\subsection{Structural properties}

In this section we analyze the details about High Resolution Transmission Electron Microcopy (HRTEM), Fourier Transform Infrared (FTIR) spectroscopy and Raman spectroscopy of DLN films. These DLN films are prepared by using liquid gas precursor as hexamethyldisilane (HMDS), hexamethyldisiloxane (HMDSO) and hexamethyldisilazane (HMDSN) with argon and nitrogen as a source gas by Plasma Enahanced Chemical Vapor Deposition (PECVD). The HRTEM image in Fig. 3 of DLN films for HMDSN precursor on silicon substrate confirm the nucleation and growth of $\mathrm{Si}_{3} \mathrm{~N}_{4}$ nanoparticles in the amorphous matrix of sizes 6-30 $\mathrm{nm}$. On the other hand, $\mathrm{SiC}$ and $\mathrm{SiOx}$ nanoparticles having same sizes were found in the DLN films using HMDS and HMDSO precursors, respectively.

The FTIR analysis of DLN films shows that the films predominantly consist of C-C, C-H, Si$\mathrm{C}$ and $\mathrm{Si}-\mathrm{H}$ bonding. FTIR and Raman spectroscopic results conform to a large extent with structural model [35-36]. DLN films are consisting of mostly two interpenetrating networks of a-Si:O and a-C:H. FTIR spectroscopy is a well known method for investigating the bonding structure of atoms by using the IR absorption spectrum which is related to vibration of atoms [37]. DLN films are deposited in same bias voltages. FTIR spectra of DLN 
films are given in Fig. 4 The main absorption band is the Si-C stretching in 750-800 $\mathrm{cm}^{-1}$ due to $\mathrm{Si}-\left(\mathrm{CH}_{3}\right)_{3}$ vibration. Strong $\mathrm{Si}-\mathrm{O}(\mathrm{Si}-\mathrm{O}-\mathrm{H})$ stretching in the range of $850-1000 \mathrm{~cm}^{-1}$ is due to Si- $\left(\mathrm{CH}_{3}\right)_{2}$ vibration. A very weak $\mathrm{C}=\mathrm{C}$ stretching peak appears in the range of $1560 \mathrm{~cm}^{-1}$, which indicates non graphite bonding of carbon [38]. The Si-H absorbance band appears in the range $2200 \mathrm{~cm}^{-1}$ region. C-H stretching band appears in $2850 \mathrm{~cm}^{-1}-3100 \mathrm{~cm}^{-1}$ region. This type of stretching is very important for DLN films. In DLN films $\mathrm{CO}_{2}$ vibration appears due to atmospheric carbon present during experiment, and $\mathrm{N}-\mathrm{H}$ vibration in $3450 \mathrm{~cm}^{-1}$ region is due to presence of nitrogen in the precursors. Here $\mathrm{C}-\mathrm{H}$ stretching and $\mathrm{Si}-\mathrm{O}$ stretching mainly comprise of the a-C:H and a-Si:O networks.
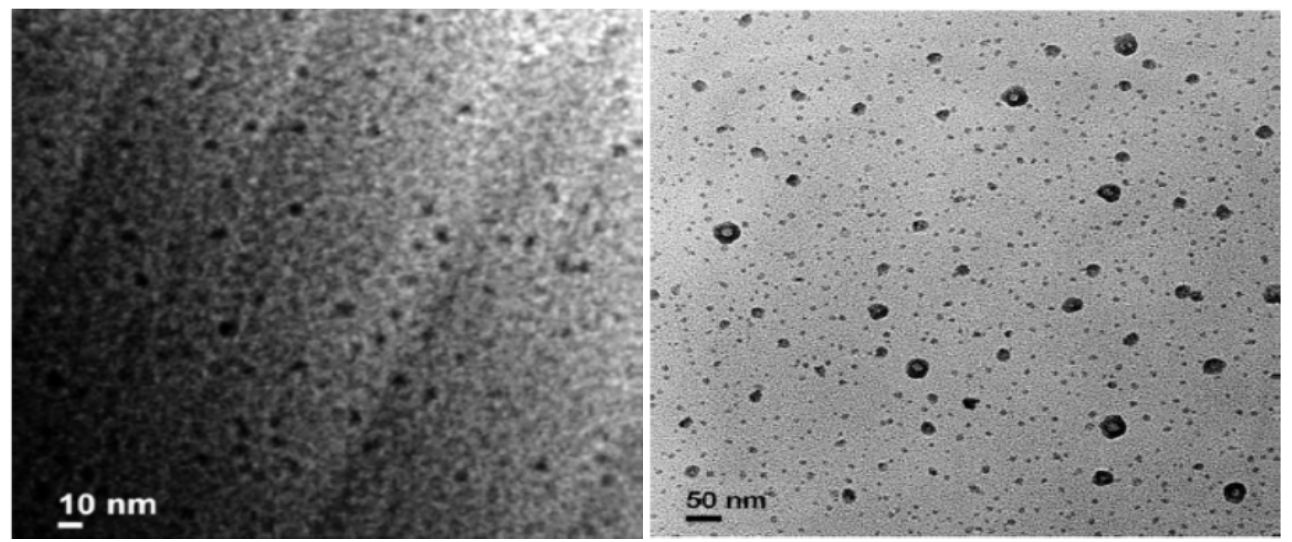

Fig. 3. HRTEM image of DLN films on silicon substrate (a) HMDSO precursor (Left fig.) (b) HMDSN precursor (right fig.), ([6], permission to reprint obtained from American Institute of Physics (AIP)).

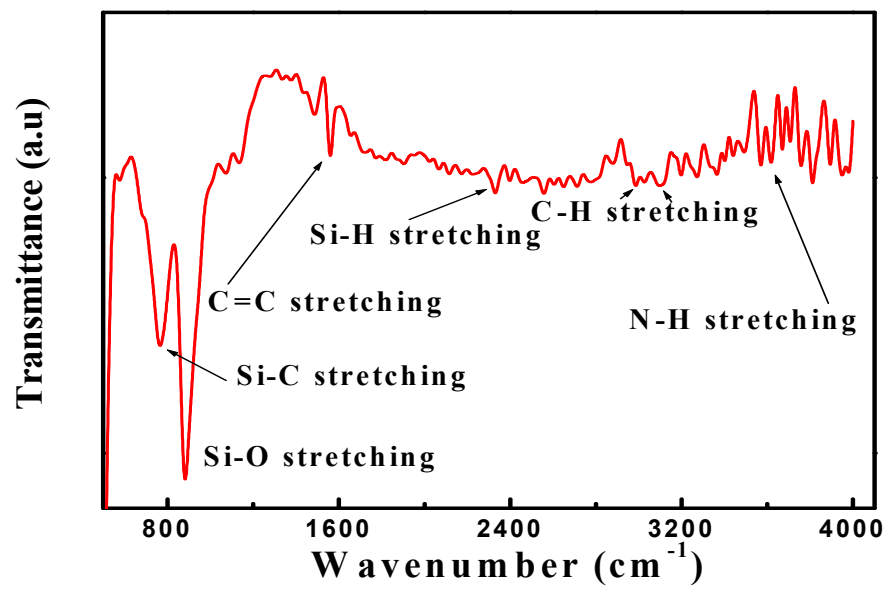

Fig. 4. FTIR spectra of DLN films. 
The first order Raman spectra of DLN films as shown in Fig. 5, which is excited by visible light, is usually decomposed into two bands, the D and G bands. Broad asymmetric diamond-like peaks in the region 1000-1800 $\mathrm{cm}^{-1}$ are typical characteristics of amorphous carbon films. Raman spectra were deconvoluted into Gaussians D and G peaks by curve fitting. DLN films are example of amorphous carbon phase, much like DLC films and probably dominated by $\mathrm{sp}^{3}$ bonding [39].

The shape of the spectra varies with substrate material composition. The position of $\mathrm{D}$ and $\mathrm{G}$ peak widths can be correlated to the film properties such as hardness, wear and electrical characteristics for conventional diamond like carbon films [40]. The position of D and G peak can be shifted due to film structure, light source of Raman spectroscopy, Gaussian fitting method and so on. Rosenblatt and Vairs have suggested the existence of new structural type of diamond-like form of carbon in which phonon frequency is around (1540 \pm 20$) \mathrm{cm}^{-1}$ depending on the distortion from the graphite structure. The D band (which is around $1330 \mathrm{~cm}^{-1}$ ) corresponds to breathing mode of $\mathrm{sp}^{2}$ atoms in hexagonal ring formed by graphite structure, which means disorder of bond angle resulting due to disappearance of the long range translation symmetry of polycrystalline graphite and amorphous carbon films, while $G$ peak (located around $1535 \mathrm{~cm}^{-1}$ ) is related to $C-C$ bond stretching vibration of all pair of $\mathrm{sp}^{2}$ atoms in both ring and chains of graphite layer for single crystalline graphite structure [41-44]. Here D means disorder G means graphite.

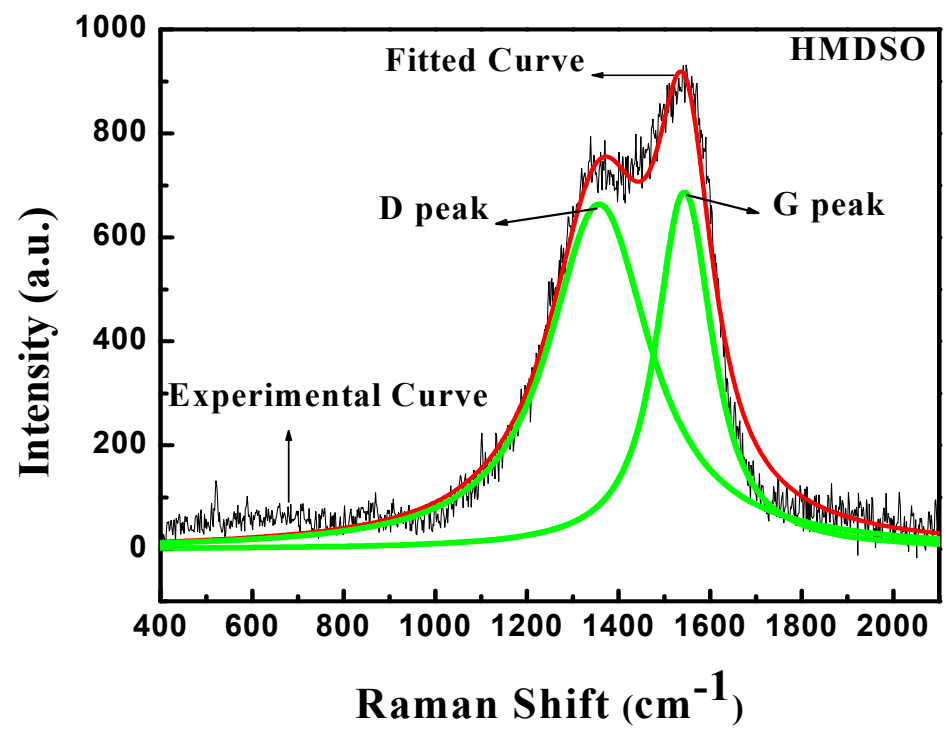

Fig. 5. Raman spectra of DLN films.

\subsection{Mechanical properties}

The method of measuring hardness and elastic modulus of thin films by nanoindentation test is explained by Oliver and Pharr [45-46]. This method is widely adopted to characterize the mechanical behavior of low dimensional materials, while the numerous refinements have been made to further improvement of its accuracy. The curve for DLN samples of loading and 
unloading forces versus displacement into the films, at maximum load up to $20 \mathrm{mN}$ are shown in Fig. 6. This figure shows a good reproducibility of the nanoindentation test [47]. The average hardness of the DLN films is measured using three indents with $20 \mathrm{mN}$ load which is around 9-17 GPa. The average reduced elastic modulus of the DLN films is measured under the $20 \mathrm{mN}$ loading force with $300 \mathrm{~nm}$ displacement which is around 90-160 GPa.

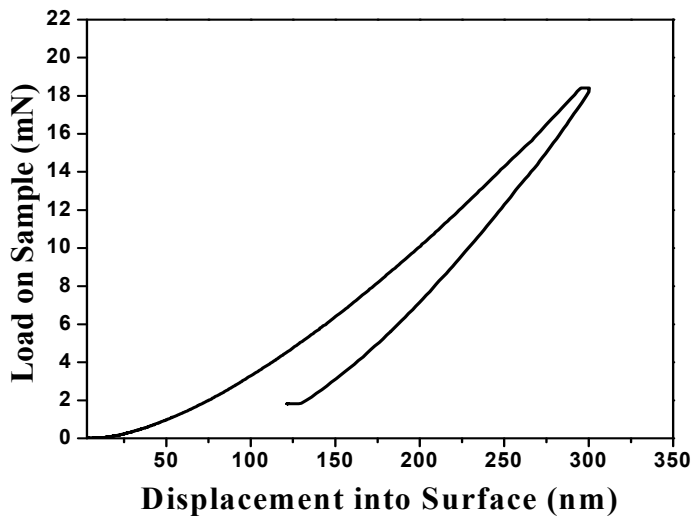

Fig. 6. Loading unloading curve of DLN sample film by Nanoindentation test for DLN films, ([6], permission to reprint obtained from Elsevier).

\subsection{Tribological properties}

To measure the friction coefficient of the DLN films by scratch test method, the loading rate was $16 \mathrm{~N}$ for both normal force and tractional force and the scratch length was about $3 \mathrm{~mm}$. The friction coefficient of the DLN films is estimated by taking the ratio of normal force to the lateral force. The variation in normal load and tractional force with respect to stroke length, and the corresponding variation in coefficient of friction against normal load, for DLN films are shown in Fig. 7.
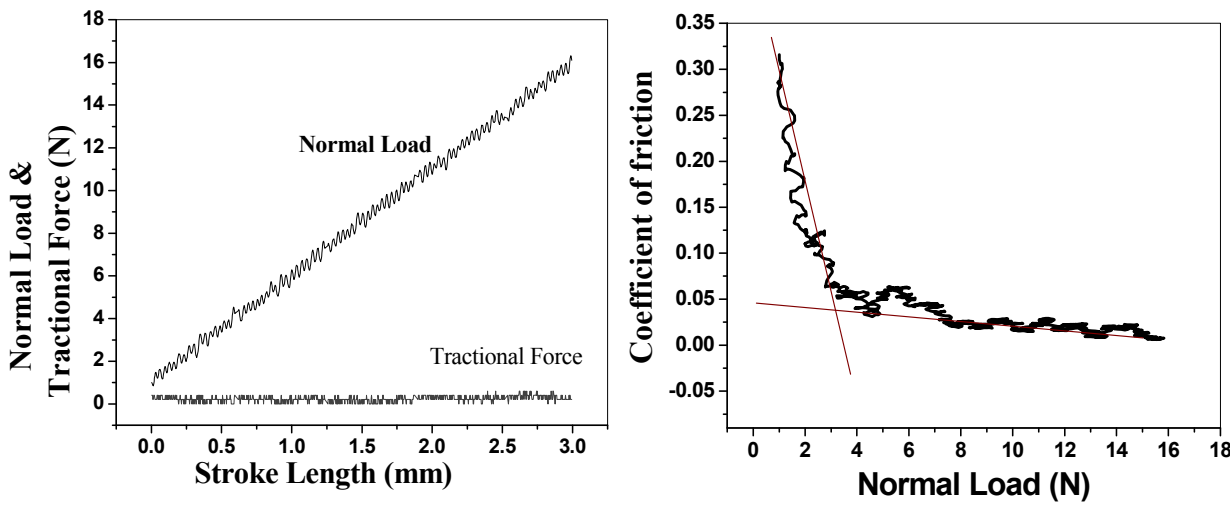

Fig. 7. Scratch Behavior for DLN coating sample (a) Variation of normal load and tractional force with stroke length (left fig), (b) Corresponding coefficient of friction variation with normal load (right fig.). 
The average friction coefficient of DLN films using conical diamond tip is estimated which is nearly $0.03-0.05$. The tribological properties of DLN films are most important for their use as protective coatings in MEMS/NEMS technology. Recently, the DLC films have been used as rigid disk for microelectromechanical or nanoelectromechanical devices. These protective coatings must have excellent wear and tear resistance, high adhesiveness and very low friction coefficient. For DLC films, the friction coefficient is around 1 but for DLN films, friction coefficient is around $0.03-0.05$ as stated above. Hence, for modern microsystems or nanosystems i.e. MEMS or NEMS, we can use the films as protective coatings compared to DLC films. The surface morphologies of DLN films are analyzed by using AFM. Fig. 8 shows the AFM image of DLN films in two dimensional (2D) and three dimensional (3D) views.

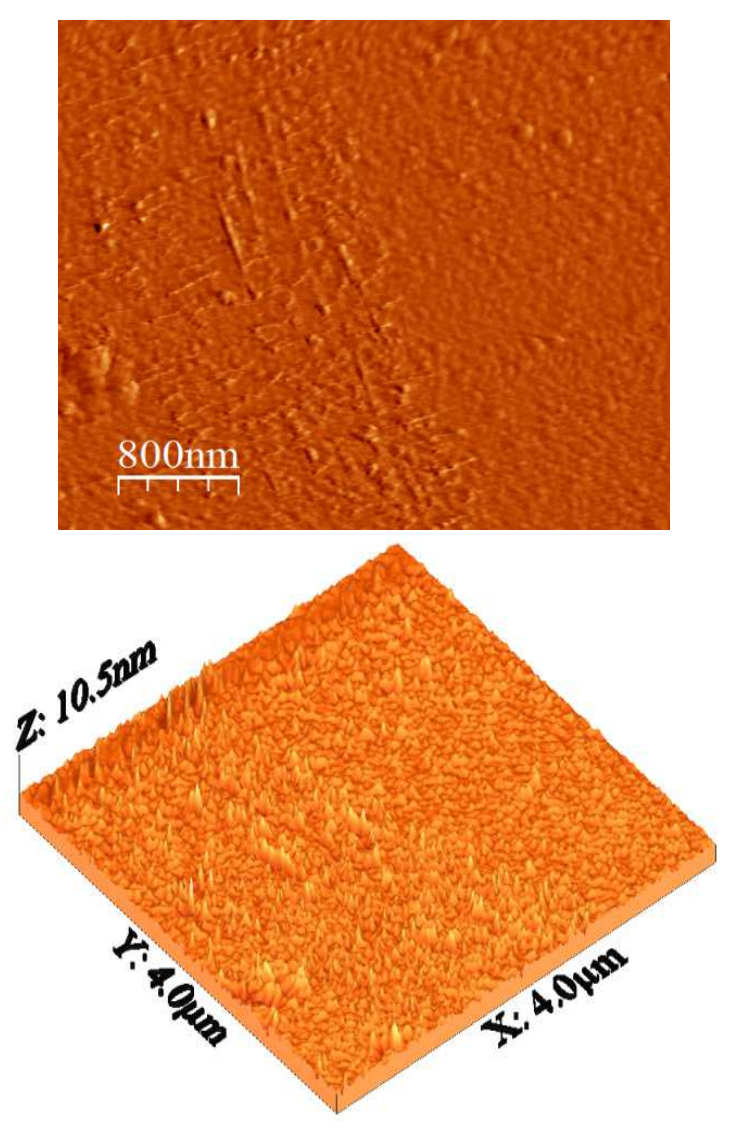

Fig. 8. The Surface morphology of DLN films deposited on silicon substrate: 2D view (top)... view (bottom).

From AFM analysis, we have estimated the mean surface roughness $\left(R_{a}\right)$ and maximum peak-to-valley height $\left(R_{\max }\right)$ of the DLN films, which are 0.292-3.2 nm and 6.1-33 nm, respectively. From this analysis, it is also confirmed that all the DLN films have no surface 
defects such as macroparticles and pinholes. Again, very less surface roughness influences the mechanical and tribological performances of the films for microscale and nanoscale devices. Hence, DLN films could provide the better performance for the applications in microelectromechanical systems (MEMS) or nanoelectromechanical systems (NEMS) devices.

\section{Diamond, DLC, DLN for MEMS technology}

Recently, the microelectromechanical systems (MEMS) and nanoelectromechanical systems (NEMS) technology are fully dominated by $\mathrm{Si}$ based materials for their fabrication. These materials have good mechanical and electrical properties for fabrication of MEMS/NEMS based sensors and actuators. Also the silicon materials have large surface area to fabricate the device. However, these materials have some limitation like high temperature withstanding capability, aggressive media, high energy particle radiation etc. For these limitations, diamond films would be good choice for fabrication of MEMS/NEMS device. Some advantageous properties of different materials including diamond and silicon are given in Table 2.

\begin{tabular}{lccccc}
\hline & Diamond & Silicon & 3C-SiC & AlN & Ni \\
\hline Young Modulus (GPa) & 1050 & 165 & 307 & 331 & 210 \\
Coefficient of thermal & 1 & 4.2 & 3.8 & 4.6 & 13.4 \\
expansion at RT (ppm/0C) & 3.52 & 2.33 & 3.21 & 3.26 & 8.91 \\
Density $\left(\mathrm{g} / \mathrm{cm}^{3}\right)$ & &
\end{tabular}

Table 2. Different material properties compared with diamond.

Recently researchers are concentrating for ceramic based materials as well as diamond to fabricate the MEMS devices instead of silicon materials. As structural properties, diamond has much more $\mathrm{sp}^{3}$ phase content, which improves the very good mechanical properties. Also much more $\mathrm{sp}^{2}$ content DLC can improve the electronic properties of materials compared to silicon material. Finally, very high hardness, high modulus of elasticity, high tensile strength, low surface roughness, low coefficient of friction, good wear rate of diamond, DLC and DLN can act as promising materials for MEMS/NEMS devices.

\subsection{Microfabrication, pattern transfer and diamond film patterning 4.1.1 Microfabrication and pattern transfer}

The standard process for microfabrication is to deposit of thin films into whole over the wafer and then need to remove the unwanted part by etch or polishing of thin films from the wafer. The microfabrication process can come in two ways, one is the directional process and another is the diffusion process. Fig. 9 shows the directional and diffuse process. The directional process which include electron or ion, photons, beam of atom which impinges into the whole wafer (such as lithography, e-beam evaporation, ion implantation etc.). The diffuse process which include the immersion process where the whole wafer surrounded by vapor, liquid or gases (By CVD or oxidation). To deposit the specific region in both process, need to use the mask in which the unwanted portion will be cover by mask and the open portion of the mask will be deposited metal or ions. The masking of the substrate can prevent the ions or atoms to react with the substrate material.

The another process is called the localized process by where the beam energy can falls into specific region of the substrate. The localized process can be divided in to focused beam 
(a)

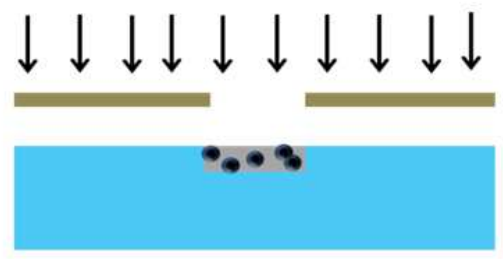

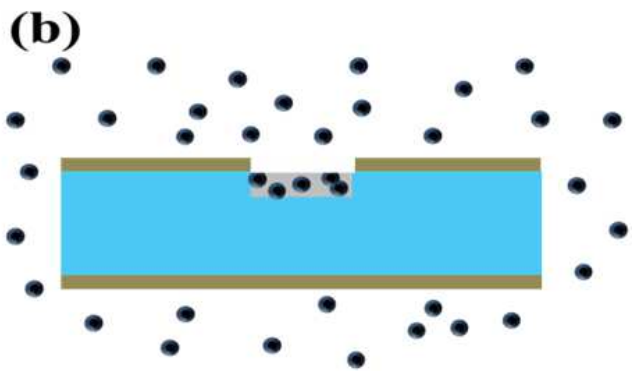

Fig. 9. (a) Directional process and (b) diffusion process

processing and microstructure assisted processing. By this process the reaction will occurred when beam of microstructure will provide energy. Fig. 10 shows the localized processing of focused beam supplies energy and microstructure provide energy.
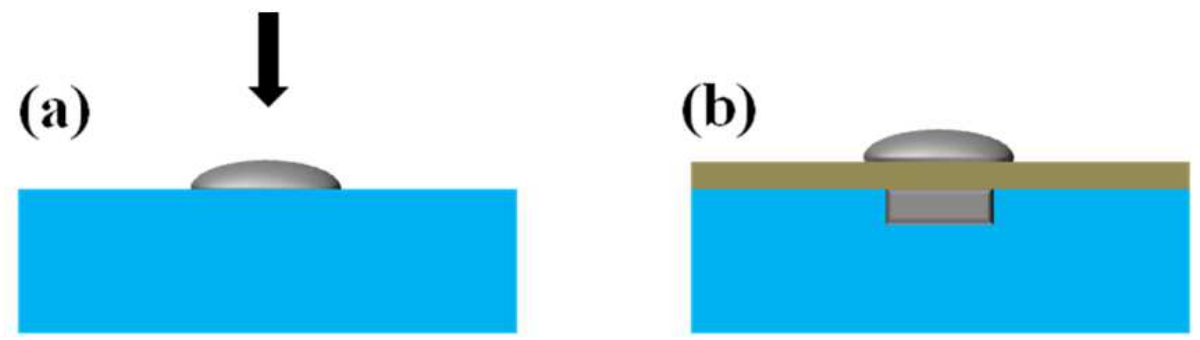

Fig. 10. Localized processing (a) focused ion beam supplies energy and (b) microstructure provide anergy.

The photolithography process is important for film patterning. By this process in the beginning the surface preparation of the films is more important. This process start from cleaning of the wafer for remove the moisture, baked the wafer, increase the adhesion promotion of the wafer by apply hexamethyldisiloxane (HMDS), $\left(\mathrm{CH}_{3}\right)_{3}-\mathrm{Si}-\mathrm{NH}-\mathrm{Si}-\left(\mathrm{CH}_{3}\right)_{3}$. The HMDS treatment can reduce the pressure to form the monolayer onto the surface of the wafer, causes the more hydrophobic of the wafer which prevents the moisture condensation. After that spin coating, soft bake, UV exposure with mask alignment, development and hard bake technique is required for whole process. After this lithographic process of the photoresist on to the wafer, the wet etching or dry etching techniques is important to pattern the any type of substrate materials. For this photolithographic pattern, the photoresist uses basically polymeric resist. This resist can dissolve or it can insoluble in the developer solution according to the positive or negative photoresist to react with UV light. The pattern is form by this polymeric resist only use of mask in front of UV light. To pattern the polymeric resist on to the substrate, different process can be applicable. This process can be divided into additive or subtractive process. By which we can add some material into the substrate or we can remove the material from the substrate by using the photoresist with mask pattern. Fig. 11 shows the different additive and subtractive process. Fig 11(a) shows the lift off process. By this process we pattern the photoresist to fall the UV light on to the mask. Then deposit the metal on the top of the wafer and finally we remove the photoresist from the wafer by development process. Fig. 11(b) is the electroplating process by which, we can deposit the metal on top of the pattern photoresist on to the wafer and finally remove the photoresist. So required metal 
can deposit on to the wafer and reaming metal will be remove from the wafer. The electroplating technique can provide high aspect ratio structure compared to lift off technique.

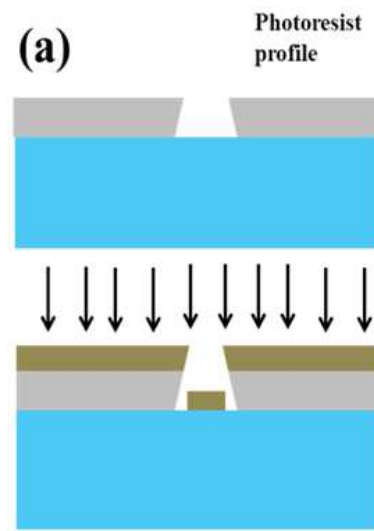

Wafer with photoresist

(b)

Photoresist

profile

Metal deposition (e-beam)
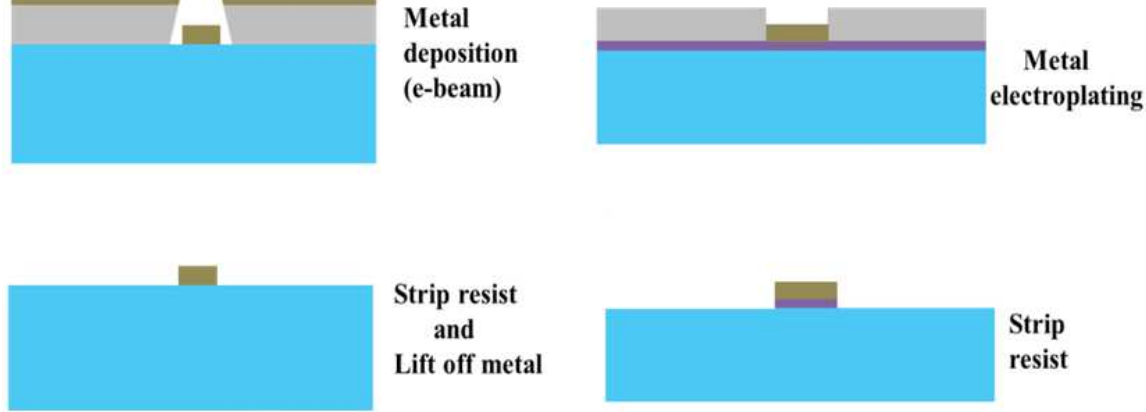

\section{Strip resist and}

Lift off metal
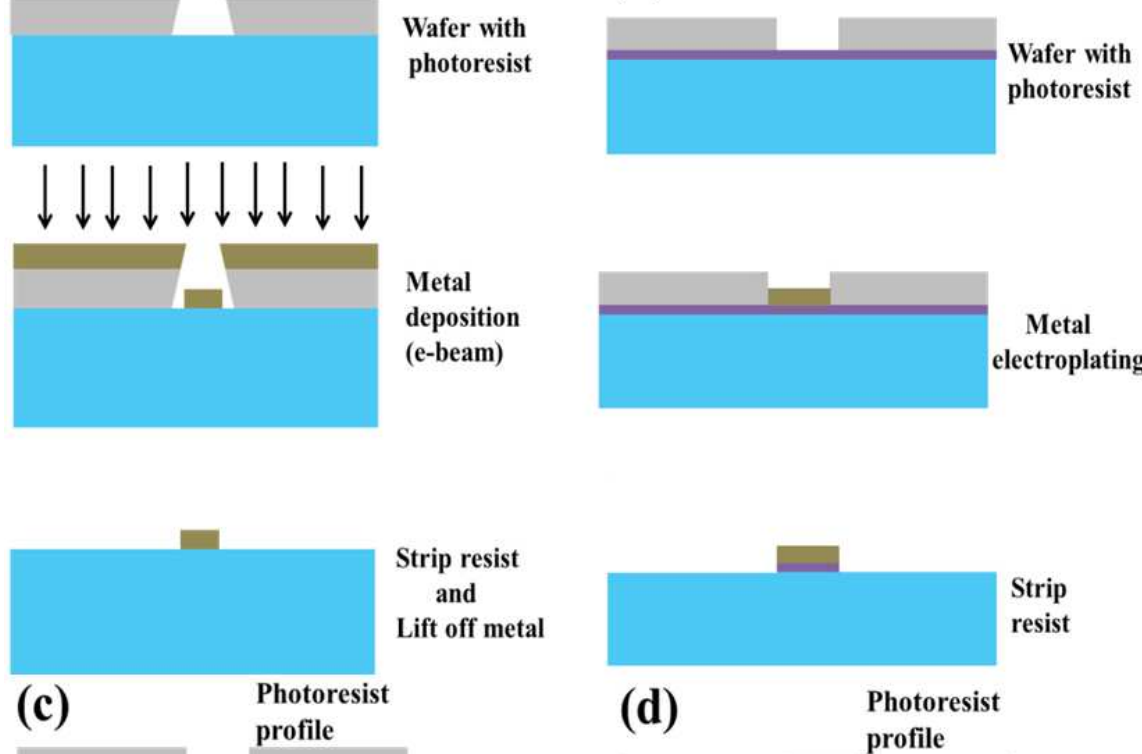

Thin film deposited in wafer

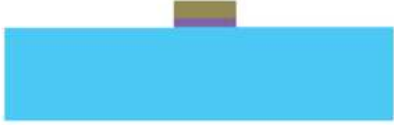

Strip

resist
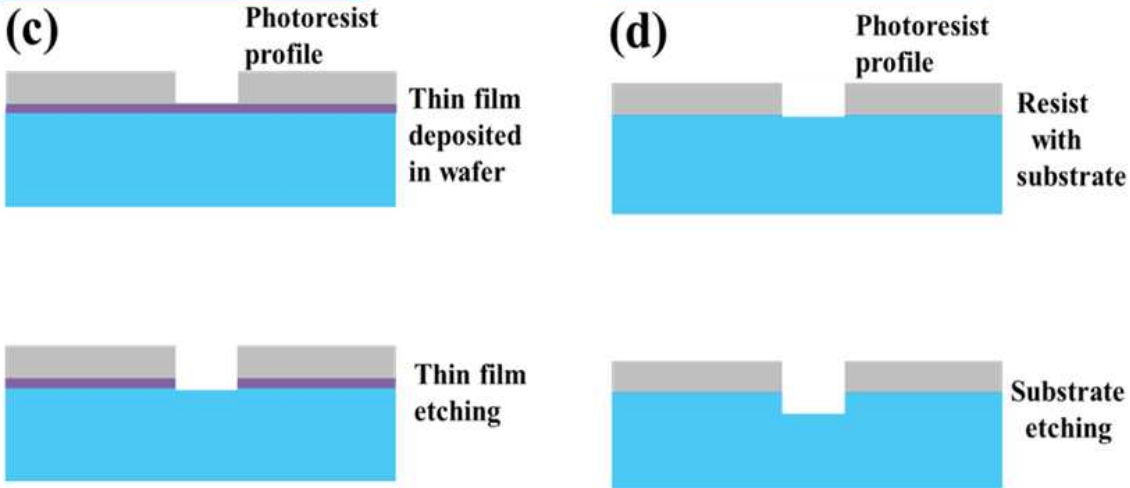

Thin film etching

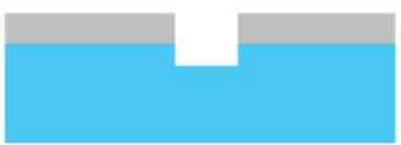

Substrate etching

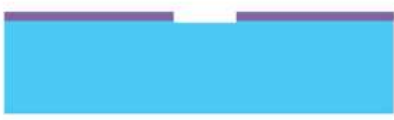

\section{Strip resist}

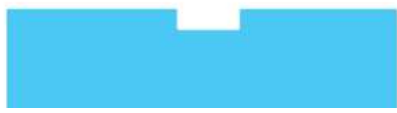

Strip

Fig. 11. Pattern transfer process, (a) lift-off technique, (b) electroplating, (c) etching of thin film, (d) etching of substrate material

In lift off technique the deposited metal film thickness should be one third of the photoresist thickness in order to make the discontinuity of the films. But electroplating technique can 
deposited the large thickness of metal with photoresist pattern compare to lift-off technique. The lift-off technique and electroplating technique is the additive process. Where as in Fig.11 (c) demonstrate the thin film etching technique by photoresist pattern, which indicate the subtractive process. Fig. 11(d) demonstrate the etching technique of substrate material by photoresist pattern (subtractive process)

\subsubsection{Diamond film patterning}

To make the pattern of diamond or diamond films is not easy task for fabrication of microstructure. The authors of this chapter are continuously trying to etch the DLN films for MEMS structure. But till now we are unable to get the success for patterning [48]. Hence, some of the diamond films (DLN) also applicable as coating materials in MEMS devices. But the other diamond films are able to pattern for MEMS device. Diamond films have very high chemical inertness. So wet chemical etching is almost impossible for diamond etching. The dry etching is possible for diamond films. The plasma based etching like Reactive Ion etching (RIE) is possible for diamond pattern. RIE has higher anisotropy, better uniformity and control, better selectivity compared to wet etching [49]. Generally RIE consists two electrode which creates the electric field to accelerate the ions towards the surface of the samples. Diamond pattern also possible by Inductive Couple Plasma (ICP). The plasma density of ICP is two times higher in order of magnitude compare to RIE plasma. In ICP, the RF power are capacitivly coupled and magnetic coil surrounded into the chamber for active species generation. The AC field is induced by RF coil which located in front of RF transducer helps to generate high density plasma due to confinement of electrons. In ICP process the plasma densities is very high around $10^{11} \mathrm{ion} / \mathrm{cm}^{2}$ [50]. By this ICP process the diamond patterning is extremely fast with good shape under low self-bias condition [51]. The oxygen based diamond etching as shown in Fig. 12, where diamond pattern with $1.7 \mu \mathrm{m}$ thick films etch by ICP [52].

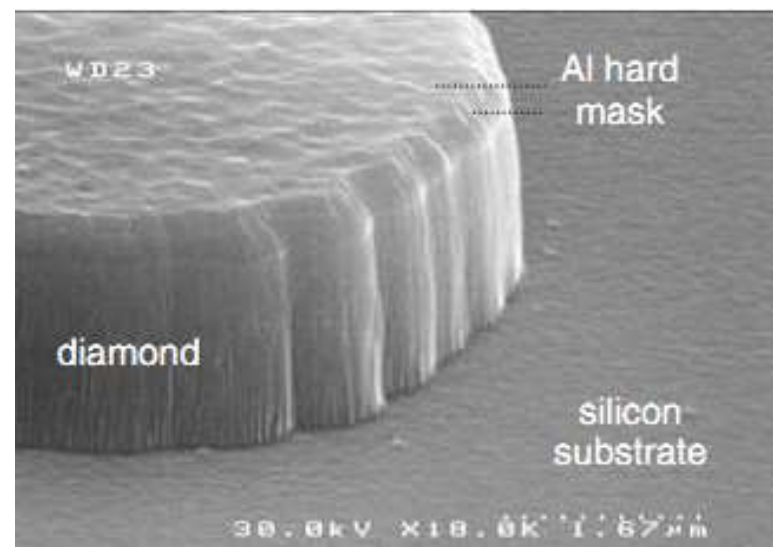

Fig. 12. Nano Crystalline Diamond (NCD) patterned by ICP etching using an Al hard mask. The etching time was 5 minutes, ([52], permission to reprint obtained from John Wiley \& Sons, Ltd.).

Another diamond pattern technique is known as Focused Ion Beam (FIB). The FIB process commercially very expensive but we can etch the material very preciously even in nm level. 
By this process focused beam of ions concentrate on a surface in order to create very small structures. This technique are widely used in microelectronics industry also. This Ion beam technique can cut the materials in very precise way. By this process, the materials can be milling to accelerate the concentrated gallium ions source on a specific site. The gallium ion source react with the surface and metallic precursor gases to produce the precise cut of conductive lines. In the FIB systems, where liquid metal ion sources are capable to form very small probes with high current densities [53]. Fig. 13 shows the FIB based diamond film pattern.

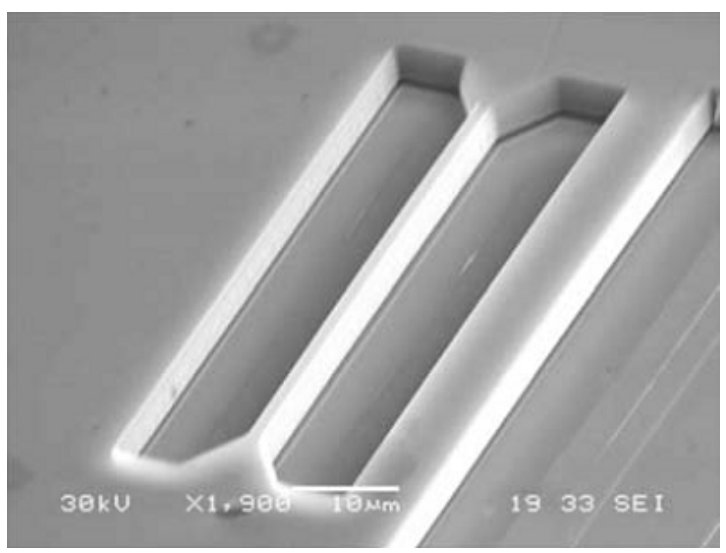

Fig. 13. Micrometer-scale bridge structure machined in single-crystal diamond released by chemical etching of graphitic layer. The graphitic layer produced by ion implantation into the diamond substrate using FIB, ([52], permission to reprint obtained from John Wiley \& Sons, Ltd.).

\subsection{Diamond, DLC, DLN films as coating material for MEMS}

Diamond, DLC and DLN films have high hardness, high modulus of elasticity, low thermal expansion coefficient, low surface roughness and low coefficient of friction and good wear properties. This all properties are very important to apply this materials as a anti-stiction coating or tribological coating on MEMS/NEMS devices. The moving parts of any microactuators, like microgears, microengine or bearing have surface contact of their won functions during operations. Due to very low coefficient of friction and surface roughness of DLC and DLN films, the films can be act as a excellent solid lubricants of microgears or microengine based MEMS devices. Very small surface roughness can reduce the friction and wear rate in microstructure component during operations [54-56]. DLC coating which can improve the lifetime of linear motor actuated by electrostatic force which drive by sliding component laterally [55].

\subsection{Diamond, DLC, DLN films for sensors and actuators applications}

Diamond, Diamond-like carbon(DLC) and Diamond-like Nanocomposite(DLN) have wide band gap, good thermal conductivity and very good piezoelectric properties, high chemical stability, high fracture strength and very high stiffness. These key properties of diamond are potentially applicable for sensing and actuating application in harsh environments [57]. For piezoresistive diamond materials mainly the nanocryastalline diamond materials are used for minimize the grain boundary influence. The piezoresistive boron doped diamond materials, 
the gauge factor must be need as small as possible to achieve the reasonable activation and for low sheet resistance. The gauge factors of the diamond films has been found in the range of 704000 and even its remain unchanged in high temperatures [58-59]. As a sensor of diamond material, the aim to measurement of mechanical effect like acceleration, pressure from piezoelectric diamond or piezoresistive diamond transducers elements. These diamond materials have been utilize for different type of sensors like pressure or UV [60-61], temperature sensors [62-63] up to $700^{\circ} \mathrm{C}$. The pressure sensors of diamond materials are based on hermitically sealed membrane structure, that can detect the bowing pressure difference. The diamond pressure sensors can be made by doped diamond as a piezoresistor or undoped diamond as a flexible diaphragm. Fig. 14, shows the boron doped piezoresistive diamond pressure sensors [64]. The undoped and boron doped diamond deposited on silicon substrate by CVD process. To improve the sensitivity of this pressure sensors, the diaphragm thickness and boron doped was varied from 62 to $5 \mu \mathrm{m}$ and 2 to $0.5 \mu \mathrm{m}$ respectively. This sensors evaluated from room temperature to $250^{\circ} \mathrm{C}$ and pressure between $0-0.07 \mathrm{MPa}$.
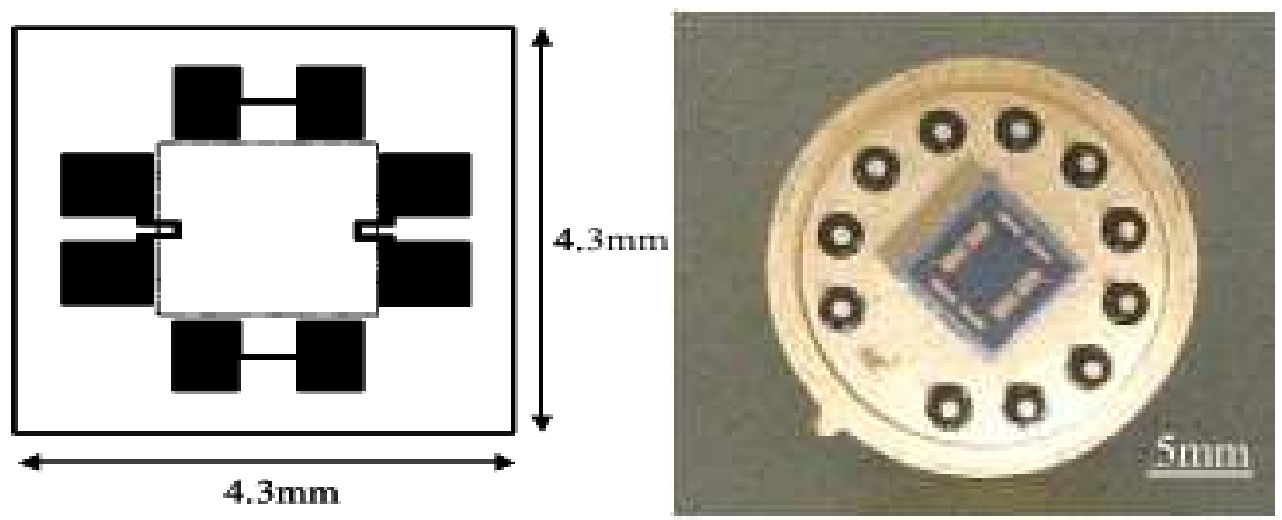

Fig. 14. Boron doped polycrystalline diamond based pressure sensors. (a) Chip layout (left fig.) (b) Pressure sensors (right fig), ([64], permission to reprint obtained from Elsevier).

Diamond films can act as a high acceleration sensors also. Diamond films have high fracture strength and high stiffness. So these films can withstand in high acceleration and shock also. Fig. 15, shows the diamond based acceleration sensors. In this figure the piezoresistive transducers elements located on the four suspended bridge which looks like whetstone bridge [65]. The sensors structure realized based on the movement of center seismic mask which suspended by four arms.

The diamond material can be act as a actuators. The microthermal actuators based on bilayer structure which delivers an out of plane motion [66] and the shape bimorph structure made by single material [67]. The bilayer which consists two layer of materials with different thermal expansion of coefficient. The deflection of bilayer actuators depends upon coefficient of thermal expansion of the materials. The diamond, DLC, and DLN have have very low coefficient of thermal expansions around $10^{-6} \mathrm{~K}^{-1}$. Hence, diamond and DLC materials can be used as bi-layer thermal actuators. The high tensile strength and very high elastic modulus of diamond, DLC, and DLN materials is the potential candidate to fabricate the contact mode micro-actuators. Also these materials used to fabricate the micro-engine, gears, rotors etc. Fig. 16, shows the diamond based micro-gears and accelerometers [68]. 
Diamond, Diamond-Like Carbon (DLC)
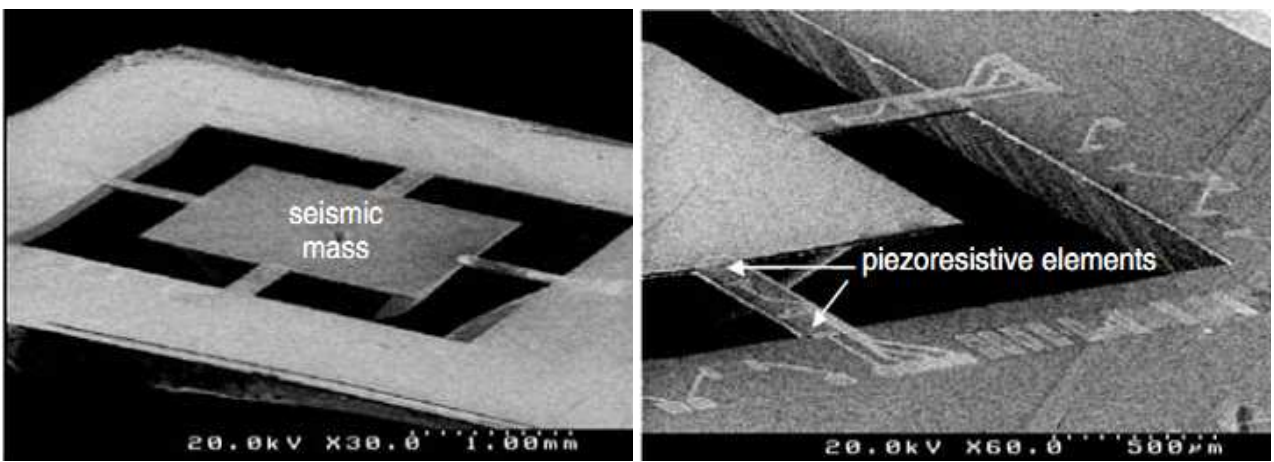

Fig. 15. Diamond material based acceleration sensors including a piezoresistive elements and seismic mask, ([52], permission to reprint obtained from John Wiley \& Sons, Ltd.).
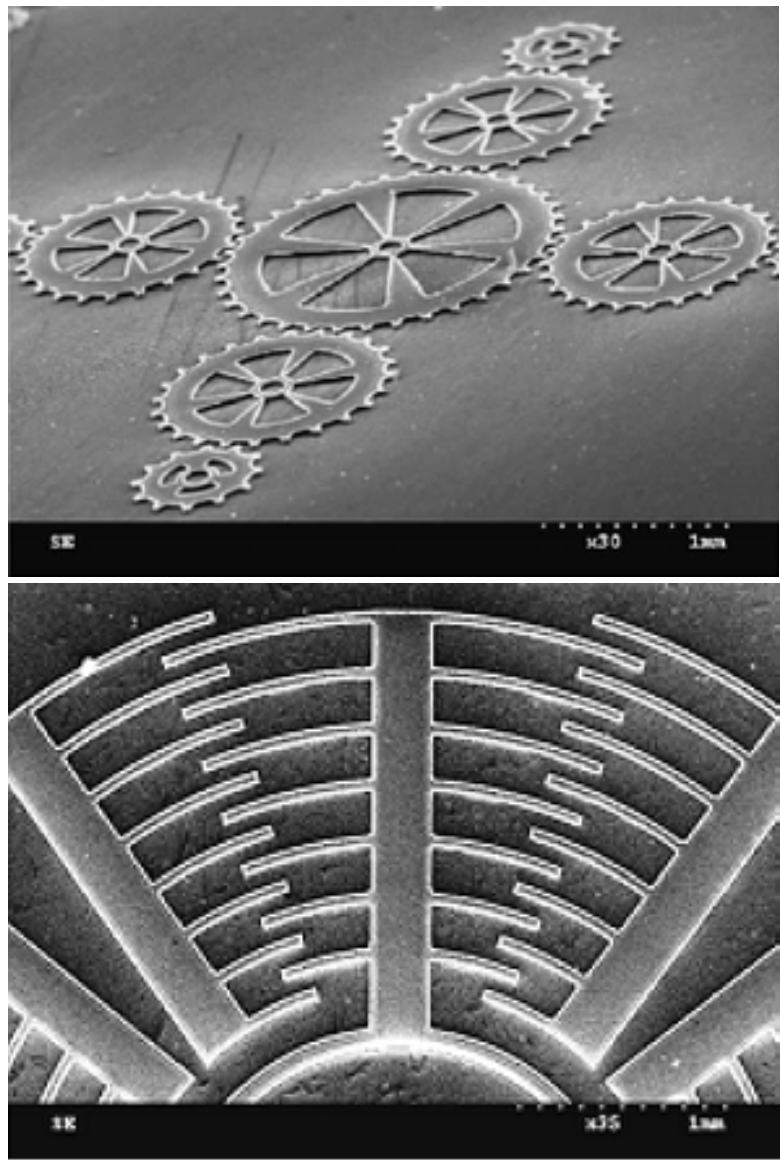

Fig. 16. Diamond based microgears (top fig.) and accelerometer (bottom fig.), ([68], permission to reprint obtained from Elsevier). 


\subsection{Diamond films for RF-MEMS application}

Diamond, DLC and DLN are potential materials for RF-MEMS applications. The RF-MEMS switches have potential for RF communications because of their high isolation and low power consumption. The RF switches, which usually based on electrostatic actuators. This RF switch can be used as diamond switch [69-73]. The boron doped diamond can be considered as semiconductor with wideband gap for fabricate the electronic device. Diamond materials are ideal candidate for RF power electronics where the important factors are like high speed, high power density, effective thermal management and passive matching components with low loss at microwave frequencies. So surface area is needed for passive component, active device, waveguide circuits and heat dissipation. The substrate needs for monolithic integrated RF power electronics in gigahertz frequency range. Leaky diamond films used in RF capacitive MEMS switches with low RF loss up to $65 \mathrm{GHz}$ have excellent electronic properties of the diamond layers [74]. Leaky diamond mode can trapped the charges and eliminating the charge injection and increases the switches reliability. Fig. 17 shows the single anchored cantilever in coplanar waveguide for $\mathrm{ON}$ and OFF switching of microwave signals. Where the centre line is bridge by the switch need to content the contact in series. In the first figure (left side) the switch was staying perpendicular way on to the waveguide. This switching is quite low because of air damping [75-76]. The very large surface area can provide the high switching speed.

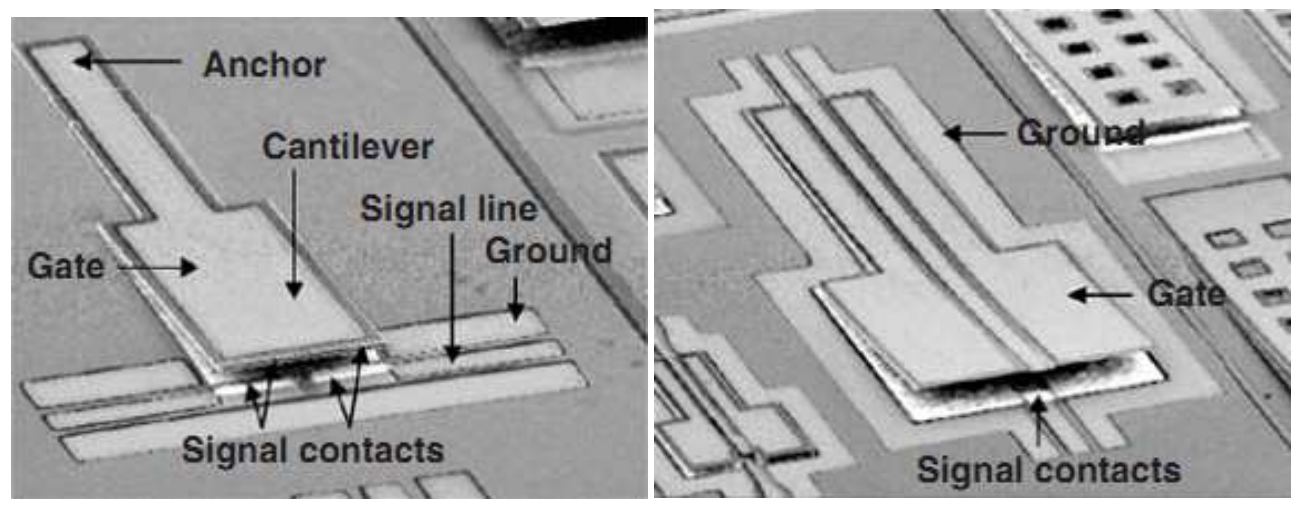

Fig. 17. Electrostatic actuators with coplanar RF waveguide. (a)The cantilever actuator closes a gap in a signal line from the side (left fig.) (b) The signal line is part of the beam itself (right fig.), ([52], permission to reprint obtained from John Wiley \& Sons, Ltd.).

In right side of the figure where cantilever is the part of coplanar waveguide pattern. The RF line of ground plane act as a electrode of the parallel plate actuator [63].

\section{Diamond, DLC, DLN for biomedical applications}

Diamond, Diamond-like Carbon(DLC) and Diamond-like Nanocomposite (DLN) thin films have high hardness, high wear resistance, high corrosion resistance and chemical inertness, low coefficient of friction, very low surface roughness, very good infrared light transparency. All of these properties are ideal for any material as a biocompatible materials. As a biocompatible material it's can be applicable for orthopedic, cardiovascular, contact lenses, catheter, prosthetic replacement etc. The biomaterial can be determine by the 
reaction of materials in biological environment [77]. The biomaterial, to apply our human body, should be chemically and biologically inert to the surrounding cells and our body fluids. In these diamond structure, they have two phase. One is $\mathrm{sp}^{2}$ hybridized carbon atoms in hexagonal ring formed by graphite structure. It is the disorder of bond angle, resulting due to disappearance of the long range translation symmetry of polycrystalline graphite and amorphous carbon films. On the other hand, the C-C stretching vibration of $\mathrm{sp}^{3}$ hybridized carbon atoms in both the rings and chains. Which indicate the disorder diamond phase. In the films if percentage of $\mathrm{sp}^{3}$ carbon is much more, then films should be good mechanical properties. The diamond and DLC films have good orthopedic applications. In our human body, the hip and knee joint are subjected the friction and wear, as a result which forms the polyethylene debris at a rate of $10^{10}$ particulates per year [78]. These phagocytosed particulates forms osteolysis, granulomatosis lesions and bone resorptions which causes the aseptic loosening of the prosthesis and pain. In last couple of years researchers are trying to apply this diamond, DLC, and DLN films coating for knee and hip replacement to decrease the wear rate. The DLC with Co-Cr alloy can reduce the significant wear rates of both sliding surfaces [79]. The amorphous diamond coatings which can improve the wear and corrosion resistance by a factor of millions compare to conventional materials [80].

The biocompatibility of DLC and DLN films have determined by the interaction of cells with DLC and DLN surface. The biocompatibility of the films can be performed by characterization of cytotsicity, protein adsorption or microphase adhesion property of the films. In the study of cell adhesion on different substrates, the increase of number of cell adhesion onto the substrate indicates that the cell have greater chance to adhere onto the substrate.

Fig. 18 shows fluoresce microscopic image of the different cells growth on different surface and Fig. 19 shows the corresponding scanning electron microscope (SEM) image of cell growth on different surface. From both of these figures, the PC 12 cells growing characteristic in neuronal process. This process interact with platinum and ultrananocrystalline diamond (UNCD) diamond surface. In silicon surface the cells formation as like closed packed islands formation.

The PC 12 cells growth on the platinum and UNCD surface exhibiting distinctive outgrowth of axons and dendrites on the surface. The growth of the PC 12 cells on the surfaces are quite less compare to HeLa cells. The figure shows that, PC 12 cells growth on UNCD surface most suitably compared to other surfaces. The area cover by PC 12 cells is almost highest in UNCD surface compared to another material surface. Which indicates that the UNCD surface have much more biocompatibility compared to other surfaces. Finally the maximum cells attachment, cell spreading and nuclear area coverage of the cell in UNCD surface is much more compered to other surfaces [81].

In medical application DLC can coat over the stent. Where a stent is a metal tube that inserted permanently into an artery. Stent helps to open an artery for blood circulation through it. Recently, the use of cardiovascular implantation of stent increasing in the world. The side effect of the artery stent lies in its release of metal ions and thrombogenecity. So it is desirable in such a material that can prevent the release of metal ions and that materials also will be hemocompatible, very high corrosion resistance and long lasting in human blood environment [82]. DLC coat stent are suitable for this pour pose. Some of the companies are made the DLC coted stent for medical purpose use. Fig. 20 shows the multilayer nanocomposite coated with DLC as an intermediate layer under the name biodiamond stent [83]. 


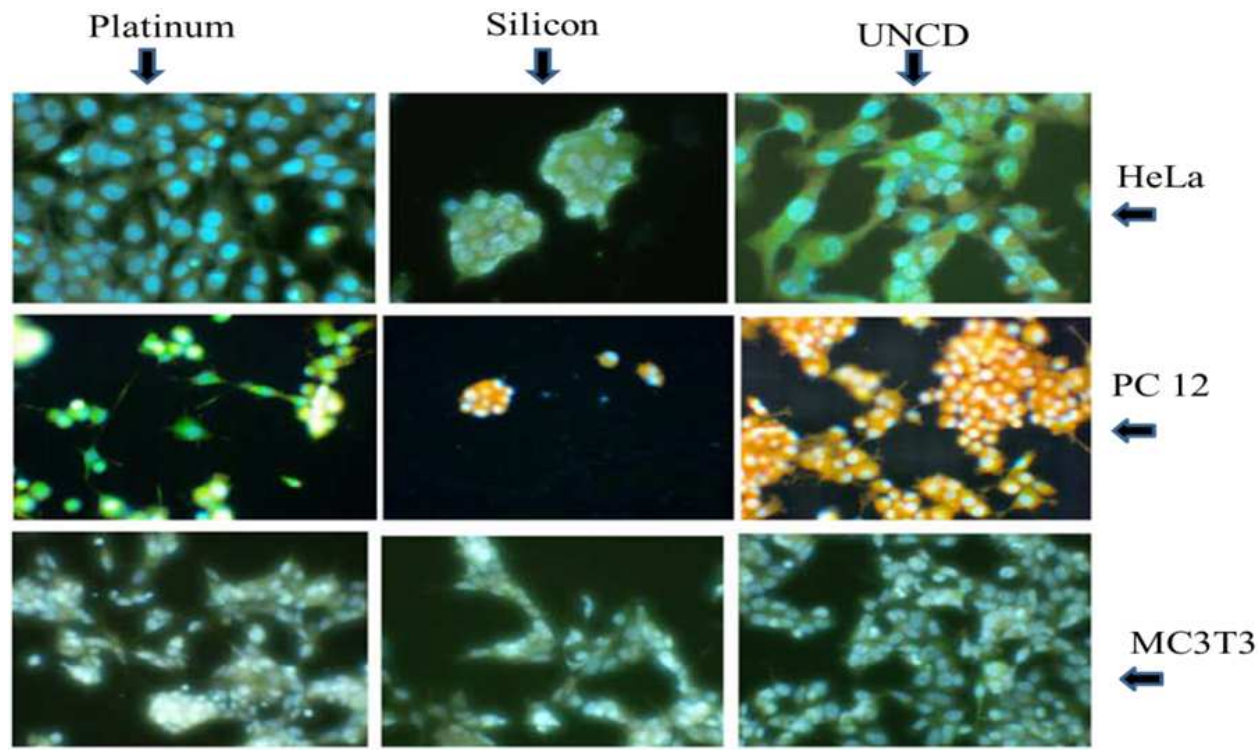

Fig. 18. Florescence microscopic image of cell attachment in platinum (first column), silicon (second column) and UNCD (third column) surfaces, ([81], permission to reprint obtained from Springer).
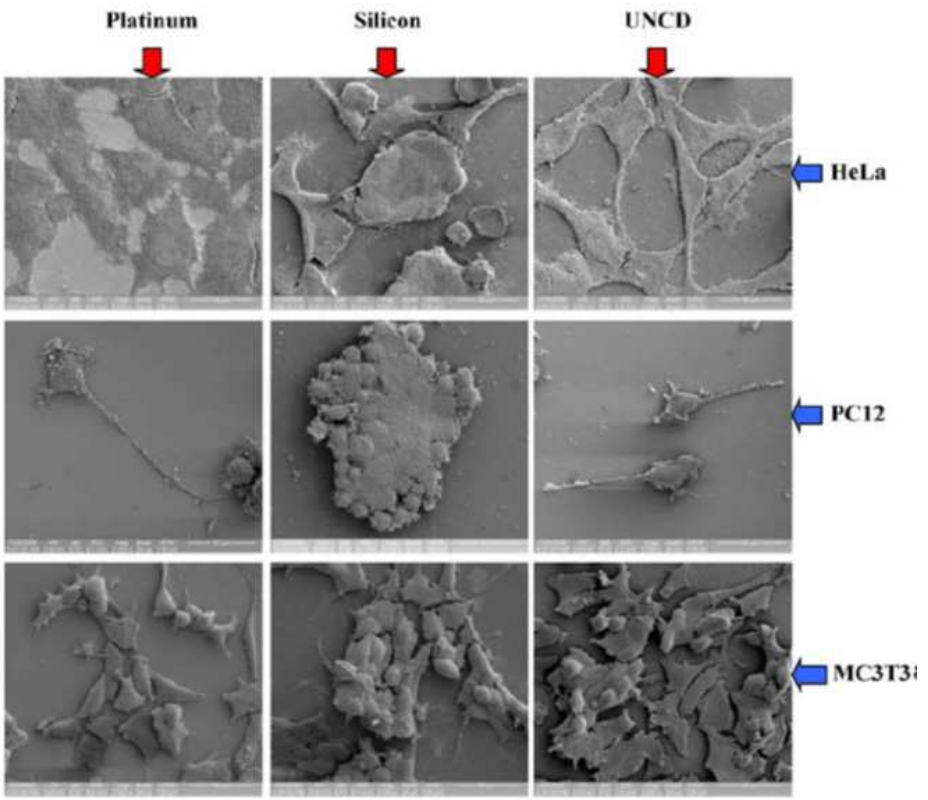

Fig. 19. Scanning Electron Microscope image of cell attachment on platinum (first column), Silicon (second column) and UNCD (third column) surfaces, ([81], permission to reprint obtained from Springer). 
The variety of studied of biocompatibility of Diamond, DLC, DLN films shows that, the materials is potentially applicable in biomedical purpose. The characterization of these materials and determination of its surface properties are necessary to correlate the different in vitro and in vivo results. The diamond coating, due to use of its long term commercially in medical purpose needs more vivo and vitro experiments.

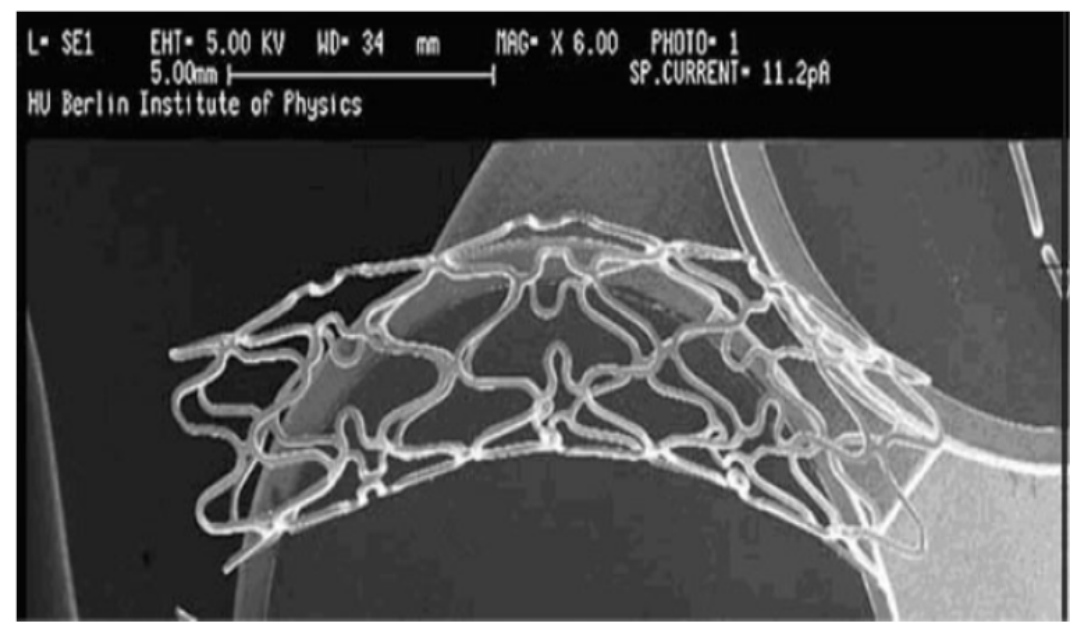

Fig. 20. A bio-diamond stent ([83], permission to reprint obtained from Elsevier).

\section{Conclusions}

In this chapter, we have described mainly the characterization technique of diamond, Diamond-Like Carbon (DLC) and Diamond-Like Nanocomposite (DLN) thin films and their application in MEMS devices. From HRTEM, FTIR, Raman Spectroscopy analysis, we conclude that the hydrocarbon groups are bonded with two interpenetrating networks (a$\mathrm{C}: \mathrm{H}$ and a-Si:O) of DLN films. And also from HRTEM analysis, DLN films contain $\mathrm{Si}_{3} \mathrm{~N}_{4}$, $\mathrm{SiC}$ and $\mathrm{SiO}_{x}$ nanoparticles within amorphous matrix, which help to reduce the compressive stress of the films. Raman Spectroscopy shows that the DLN films should have higher concentrations of $\mathrm{sp}^{3}$ carbon than the conventional DLC films. High $\mathrm{sp}^{3}$ contents influence the mechanical properties of the films as a result, hardness and elastic modulus will increase due to higher $\mathrm{sp}^{3}$ content. From our all characterize technique we can conclude that diamond, Diamond-Like Carbon (DLC) and Diamond-Like Nanocomposite (DLN) thin films have very high hardness, high modulus of elasticity, high tensile strength, high thermal conductivity, very less surface roughness, low coefficient of friction low thermal expansion and good wear properties. All of these properties are unique material properties for application in MEMS/NEMS device. The excellent tribological properties of the diamond films are very useful to improve the stiction, friction and wear resistance of MEMS/NEMS based microcomponent. The chemical inertness and high temperature withstanding capability of this films can be useful for biosensor and microfluidic devices. In our microfabrocation part we discussed different thin film deposition technique with different pattern like lift-off, electroplating, thin film etching and substrate etching technique. Finally we have discussed the diamond film patterning and their application in 
MEMS/NEMS technologies like pressure sensor, accelerometer and different actuators. As a biocompatible material, diamond films have lot of applications in biomedical purpose such as orthopedic, cardiovascular, contact lenses, catheter, prosthetic replacement etc. Also the UNCD films have much more cells attachment, cell spreading and nuclear coverage area compared to another materials. Which confirms the biocompatibility issue of UNCD materilas. The chemical inertness, biocompatibility and excellent thermal conductivity of diamond, DLC and DLN films can be exploited in the development of biosensors, microfluidic device for lab-on-a-chip and implantable medical devices applications.

\section{Acknowledgments}

The authors T.S. Santra, P. Patel and T.K. Barik are gratefully acknowledge Dr. Arnab Bhattacharyya, National Metallurgical Laboratory (NML), Jamshedpur, India, for kind help to write this chapter.

\section{References}

[1] Verpoorte et al.( 2003). Proc. IEEE 91930

[2] Vellekoop.M.J \& Kostner.S. (September 2006). Proc. 20 th Eurosensors, Vol 1 pp 28 (Goteborh, Sweden)

[3] Jacob-Cook et al. (1996). J. Micromech. Microeng, Vol .6, pp.148

[4] Tsai.N.C \& Sue.C.Y .(2007). Sensors Actuators, Vol.136, pp. 178

[5] Brown et al. (1998). IEEE Trans. Microw. Theory Technol. Vol.46, pp. 1868

[6] Santra et al.(2010). J. Appl. Phys,Vol.107, No. 124320-1-124320-9 and Santra et al. (2011). Surf. Coat. Technol., Vol. 206, pp. 228-233

[7] Morshed et al. (2003). J. Surface and Coating Technology, Vol.541, pp.163-164

[8] Silva et al .(1988). Amorphous carbon: State of the Art (World Scientific, Singapore)

[9] Lifshitz et al.(1999). Diamond Relat. Mater, Vol.8, pp.1659

[10] Bushan et al. (1999). Diamond Relat. Mater, Vol.8, pp.1985

[11] Tillmann et al. (2007). Thin Solid Films, Vol.516, pp.262

[12] Shirakura et al. (2006). Thin Solid Film, Vol.494, pp.84

[13] Liu et al .(2003). Thin Solid Films, Vol.36, pp.244

[14] Das et al. (2007). Materials in Medicine, Vol.18, No 3, pp.493

[15] Spengen et al.(2003). J.Adhes. Sci. Technol, Vol.17, pp.563

[16] Tanner et al.(1999). Microelectron. Reliab, Vol 39, pp.401

[17] Tanner et al. (April 2000). Proc. IEEE Int. Reliability Phys, Symp.(San Jose) pp. 139

[18] http://www.sandia.gov/media.NewsRel/NR2000/diamond.htm.

[19] Jacob, W \& Moller, w. (1993). Appl. Phy. Lett., Vol. 63, pp. 1771-1773.

[20] Weiler et al. (1994). Appl. Phy. Lett., Vol. 64(21), pp. 2797-2799.

[21] Ferrari .A.C \& Robertson, J. (2004). Phil. Trans. R. Soc. Lond., Vol. A362, pp. 2477-2512.

[22] Mekenzie, D.R. (1996). Rep. Prog. Phys. Vol. 59, p. 1611.

[23] Blormen et al. (1999). Sensors Actuators, Vol.73, p.24.

[24] Blormen et al. (1999). Sensors Actuators, Vol. 78, p. 41.

[25] Fu et al. (2000). Mater. Sci. Eng, A., Vol. 282, pp. 38-48.

[26] Fu et al. (1999). J. Mater. Sci., Vol. 34, pp. 2269-83.

[27] Fu et al. (2003). Thin Solid Films, Vol. 424, pp. 107-114.

[28] Boundina et al. (1992). Diamond and Related Materials I, pp. 380-387. 
[29] Grill. A, (1997). Surf. Coat.Technol, Vol. 507, pp. 94-95.

[30] Robertson. J. (2002). Mater. Sci. Eng. Rep, Vol. R37, p. 129.

[31] Luo et al. (2007). J. Micromech. Microeng., Vol. 17, pp. S147-S163.

[32] Tamor, M.A. \& Vassell, W.C. (1994). J. Appl. Phys, Vol. 76, p. 3823.

[33] Robertson, J. (1983). Adv. Phys, Vol. 32, p.361.

[34] Robertson, J. (1994). Pure Appl. Chem., Vol. 66, p.1789.

[35] Dorfman, V.F. \& Pypkin, B.M. (1991). Surf. Coat. Technol., Vol. 48, p.193.

[36] Dorfman. V.F. \& Pypkin, B.N. (1994). U.S. Patent, Patent Number: 5, 352, 493.

[37] Skoog et al. (1998). Principles of Instrumental Analysis, 4th ed. (Harcourt Brace \& Company, Philadelphia), Chaps. 16.

[38] Nadler et al. (1984). Thin Solid Films, Vol. 116, p. 241.

[39] Tallant et al. (1995). Daimond Relat. Mater., Vol. 4, p. 191.

[40] Marchon et al. (19991). J. Appl. Phys., Vol. 69, p. 5748.

[41] Tuinstra, F. \& Koenig, J.L. (1970). J. Chem. Phys., Vol. 53, p. 1126.

[42] Dillion, R.O. \& Woollam, J.A. (1984). Phys. Rev., Vol. B29, p. 3482.

[43] Yang et al. (2003). Materials Letters, Vol. 57, p. 3305.

[44] Wu et al. (2008). Thin Solid Films, Vol. 517, pp. 1141-1145.

[45] Oliver, W.C. \& Pharr. G.M. (1992). J. Mater. Res., Vol. 7, p. 1564.

[46] Oliver, W.C. \& Pharr, G.M. (2004). J. Mater. Res., Vol. 19, p. 3.

[47] Savvides, N. \& Bell, T.J. (1992). J. Appl. Phys., Vol. 72, p. 2791.

[48] Kundu et al. (2009). Advanced Material Research, Vol. 74, pp. 269-272.

[49] Rahman et al. (2001). J. Appl. Phys., Vol. 89, p. 5.

[50] http://www.axinst.com

[51] Enlund et al. (2005). Carbon, Vol. 43, pp.1839-1842.

[52] Sussmann, R.S. (2009). CVD diamond for electronic device and sensors, Wiley \& Sons, ISBN-978-0-470-06532-7.

[53] Olivero et al. (2005). Adv. Mat., Vol. 17(20), pp. 2427-2430.

[54] Beerschwinger et al. (1994). J. Micromech. Microeng., Vol. 4, p. 95.

[55] Smallwood et al. (2006). Wear, Vol. 260, p. 1179.

[56] Liu, H.W. \& Bhushan, B. (2003). J. Vac. Sci. Technol., Vol. A 21, p. 1528.

[57] Kohn et al. (2007). (Eds), Elsevier pp. 131-181.

[58] Tang et al. (2006). Diam. Rel. Mater., Vol. 15, p. 199.

[59] Sahli, S. \& Aslam, D.M. (1998). Sensors Actuators, Vol. A 71, p. 193.

[60] Davidson et al. (1999). Diam. Rel. Mater., Vol. 8, p. 1741.

[61] Ciancaglioni et al. (2005). Diam. Rel. Mater., Vol. 14, p. 526.

[62] Ran et al. (1993). Diam. Rel. Mater., Vol. 2, p. 793.

[63] Yang et al. (1997). Diam. Rel. Mater., Vol. 6, p. 394.

[64] Yamamoto et al. (2005). Diam. Rel. Mater., Vol. 14, pp. 657-660.

[65] Kohn et al. (1999). Diam. Rel. Mater., Vol. 8, pp. 934-940.

[66] Baltes et al. (1998). Proc. IEEE, Vol. 86, p. 1660.

[67] Hickey et al. (2002). Aci. Technol., Vol. A 23, p. 71.

[68] Fu et al. (2003). J. Mat. Proc. Technol., Vol. 132, p. 73.

[69] Adamschik et al. (2002). Diam. Rel. Mater., Vol. 11, pp. 672-676.

[70] Kohn et al. (12-15 May, 2002). 23rd International Conference on Microelectronics (MIEL), Nis, Yugoslavia, Proceedings, pp. 59-66. 
[71] Schmid et al. (12-15 May, 2002). 23rd International Conference on Microelectronics (MIEL), Nis, Yugoslavia.

[72] Kohn et al. (8-13 June, 2003). Evaluation of CVD diamond for heavy duty microwave switches, IEEE MTT-S International Microwave Symposium, Philadelphia, PA, USA, Digest, pp. 1625-1628.

[73] Schmid et al. (2003). Semicond. Sci. Technol., Vol. 18, pp. S72-S76.

[74] Chee et al. (2005). Proc. 13th GAAS Symp. (Paris).

[75] Kusterer et al. (2006). New Diamond and Frontier Carbon Technology, Vol. 16 (6), pp. 295-321.

[76] Schmid. P. (2006). Ph. D thesis, University of Ulm, Germany.

[77] Von Recum, A.F. (1999). Editor. Handbook of Biomaterials Evaluation.Philadelphia: Taylor and Francis.

[78] Dearnaley et al. (2005). Surf. Coat. Technol., Vol. 200, pp. 2518-2526.

[79] Sheeja et al. (2005). Surf. Coat. Technol, Vol. 190, p. 231.

[80] Lappalainen, R .(May, 2005). Intl. Conf. on Metallurgical Coatings and Thin Films, San Diego, $C A$.

[81] Bajaj et al. (2007), Biomed. Microdevices, Vol. 9, pp. 787-794.

[82] Roy, R.K. \& Lee. K.R. (2006). J. Biomedical Material Research, Part B, Applied Biomaterials, DOI 10.1002/jbmb

[83] Choi et al. (2006). Diamond Related Material, Vol. 15, pp. 38-43. 


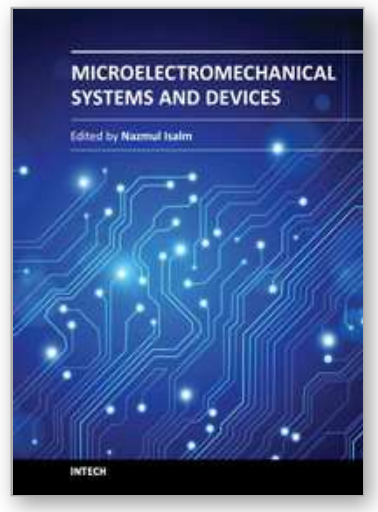

\author{
Microelectromechanical Systems and Devices \\ Edited by Dr Nazmul Islam
}

ISBN 978-953-51-0306-6

Hard cover, 480 pages

Publisher InTech

Published online 28, March, 2012

Published in print edition March, 2012

The advances of microelectromechanical systems (MEMS) and devices have been instrumental in the demonstration of new devices and applications, and even in the creation of new fields of research and development: bioMEMS, actuators, microfluidic devices, RF and optical MEMS. Experience indicates a need for MEMS book covering these materials as well as the most important process steps in bulk micro-machining and modeling. We are very pleased to present this book that contains 18 chapters, written by the experts in the field of MEMS. These chapters are groups into four broad sections of BioMEMS Devices, MEMS characterization and micromachining, RF and Optical MEMS, and MEMS based Actuators. The book starts with the emerging field of bioMEMS, including MEMS coil for retinal prostheses, DNA extraction by micro/biofluidics devices and acoustic biosensors. MEMS characterization, micromachining, macromodels, RF and Optical MEMS switches are discussed in next sections. The book concludes with the emphasis on MEMS based actuators.

\title{
How to reference
}

In order to correctly reference this scholarly work, feel free to copy and paste the following:

T. S. Santra, T. K. Bhattacharyya, P. Patel, F. G. Tseng and T. K. Barik (2012). Diamond, Diamond-Like Carbon (DLC) and Diamond-Like Nanocomposite (DLN) Thin Films for MEMS Applications, Microelectromechanical Systems and Devices, Dr Nazmul Islam (Ed.), ISBN: 978-953-51-0306-6, InTech, Available from: http://www.intechopen.com/books/microelectromechanical-systems-and-devices/diamonddiamond-like-carbon-dlc-and-diamond-like-nanocomposite-dln-thin-films-for-mems-applications-

\section{INTECH}

open science | open minds

\author{
InTech Europe \\ University Campus STeP Ri \\ Slavka Krautzeka 83/A \\ 51000 Rijeka, Croatia \\ Phone: +385 (51) 770447 \\ Fax: +385 (51) 686166 \\ www.intechopen.com
}

\author{
InTech China \\ Unit 405, Office Block, Hotel Equatorial Shanghai \\ No.65, Yan An Road (West), Shanghai, 200040, China \\ 中国上海市延安西路65号上海国际贵都大饭店办公楼405单元 \\ Phone: +86-21-62489820 \\ Fax: +86-21-62489821
}


(C) 2012 The Author(s). Licensee IntechOpen. This is an open access article distributed under the terms of the Creative Commons Attribution 3.0 License, which permits unrestricted use, distribution, and reproduction in any medium, provided the original work is properly cited. 